\title{
A PERCEPÇÃO DOS PROFESSORES DO CURSO DE ADMINISTRAÇÃO DE UMA UNIVERSIDADE FEDERAL DO NORDESTE SOBRE O PROCESSO SELETIVO PARA DOCENTES THE PERCEPTION OF PROFESSORS OF MANAGEMENT COURSE OF A NORTHEAST FEDERAL UNIVERSITY ON THE SELECTION PROCESSES FOR PROFESSORS
}

Data de submissão: 09/07/2013 Aceite: 29/09/2015

Francisco Sergio de Almeida Neto ${ }^{1}$ Elisabete Stradiotto Siqueira² Erlaine Binotto ${ }^{3}$

\section{RESUMO}

O objetivo deste artigo foi analisar a percepção que os docentes do curso de Administração de uma universidade federal do nordeste têm sobre o processo de seleção, do qual participaram enquanto candidatos. O estudo se constituiu em uma pesquisa exploratória com dados qualitativos complementados por dados quantitativos. Esta universidade, que participa do REUNI, foi escolhida como objeto de análise em função do processo de expansão que vem passando nos últimos anos. Fizeram parte dessa pesquisa $88 \%$ dos docentes do curso de Administração da universidade. Os dados mostram que apesar de na universidade, ensino, pesquisa e extensão comporem o tripé que sustenta o fazer acadêmico, não foi isso que se pode perceber na concepção dos docentes pesquisados como um valor importante no processo de seleção. Constatou-se que as bancas avaliadoras são os principais alvos de críticas dos candidatos. Necessita-se de mais transparência, desde a formação da banca até seus critérios de avaliação.

Palavras-chave: Processo Seletivo, Docentes, Universidade Federal

\footnotetext{
1 Possui Graduação em Administração pela Universidade Federal Rural do Semi-Árido (UFERSA), mestrado em Administração pelo Programa de Pós-Graduação em Administração - PPGA - da Universidade Federal da Paraíba. Atualmente é professor do Instituto Federal de Educação, Ciência e Tecnologia do Rio Grande do Norte (IFRN). Paraíba. Rio Grande do Norte. Brasil. E-mail: sergioneto15@hotmail.com

2 Possui Bacharel em Administração pela Universidade Metodista de Piracicaba, mestrado em Administração pela Pontifícia Universidade Católica de São Paulo e doutorado em Ciências Sociais pela Pontifícia Universidade Católica de São Paulo. Atualmente é professor adjunto da Universidade Federal Rural do Semi-Árido. Mossoró. Rio Grande do Norte. Brasil. E-mail: betebop@uol.com.br

3 Possui graduação em Administração pela Universidade Federal de Santa Maria, especialização em Fundamentos Teórico Metodológicos de Ensino pela Universidade de Cruz Alta, mestrado e doutorado em Agronegócios pela Universidade Federal do Rio Grande do Sul. Atualmente é professora Adjunta IV na Universidade Federal da Grande Dourados. Dourados. Mato Grosso do Sul. Brasil. E-mail: e-binotto@uol.com.br
} 


\section{ABSTRACT}

This paper has aimed to analyze the perception of the administration course professors of a federal university at northeast that take part of selection processes have about the selection process which involved as applicants. The study consisted of exploratory research with qualitative complemented by quantitative data. This university is part of the REUNI program was chosen as analysis considering the expansion process that have been occurring on the last years. Took part in this survey $88 \%$ of the professors from administration course of the university. The data show that although in the university, teaching, research and extension compose the tripod that supports the academic making, this can not be perceived in the conceiving of the professors surveyed as an important value in the selection process. It is concluded that the board of assessment is the main target of criticism of the candidates. It needs more transparency, from the choice of the board to their evaluation criteria.

Keywords: Selection Process, Professors, Federal University

\section{INTRODUÇÃO}

A seleção de pessoal nas organizações sempre se constituiu em um processo complexo, por envolver critérios objetivos e subjetivos. Sua evolução acompanha as transformações da área de recursos humanos no decorrer das últimas décadas, desde a criação do departamento de pessoal (MARRAS, 2000) até a perspectiva dos recursos humanos estratégicos, alinhado às estratégias corporativas (ULRICH, 2000).

Nesse percurso de desenvolvimento da área, a seleção de pessoas partiu da noção de perfil adequado a um determinado cargo, até mais recentemente, a busca de talentos, ou seja, a busca por pessoas com habilidades cognitivas, técnicas e conceituais capazes de contribuir com a inovação organizacional (QUEIROZ; ALBUQUERQUE; MALIK, 2013). Para Michaels, Handfield e Axelrod (2002) talento é o conjunto de habilidades de uma pessoa - seus dons, conhecimento, experiência, inteligência, discernimento, atitude, caráter e impulsos inatos, o que inclui sua capacidade de aprender.

Essa nova perspectiva do processo de seleção, na busca de talentos com foco nas competências, está relacionada com as mudanças na organização do trabalho. Essas têm sido discutidas por autores como Castells (1999), Sennet (2000), Beck (1997), Heloani (1994), Toffler (2007) e embora não haja consenso sobre como as novas características do trabalho afetam a subjetividade do trabalhador, todos afirmam que há uma tendência de valorizar a dimensão intelectual em detrimento da atuação física.

A competência está alem da tarefa, situa-se na interseç̧ão entre a pessoa (socialização), sua formação educacional e experiência profissional, "implica saber como mobilizar, integrar e transferir os conhecimentos, recursos e habilidades, num contexto profissional determinado" (FLEURY; FLEURY, 2001, p. 187).

Fleury e Fleury (2001) consideram a existência de dois tipos de competência, a individual, relacionada a verbos como saber agir, mobilizar recursos, integrar saberes, aprendizado, estratégia e responsabilidade e a competência organizacional, que é aquela que permite que as ações da empresa agreguem valor econômico aos produtos e valor social para os indivíduos.

Em um contexto de competitividade acirrada, as organizações empresariais estão cada vez mais exigindo um processo de seleção mais rigoroso, focando sempre nas competências das pessoas, pois o objetivo maior das empresas é tornarem-se mais competitivas no mercado (BITENCOURT, 2004). Assim como nas empresas, no serviço público, as competências organizacionais e individuais têm sido buscadas, não apenas para atingir desempenhos mais eficientes, mas para facilitar uma mudança cultural e uma consequente modernização na gestão pública (HORTON, 2000). 
No que se refere à contratação no setor público, através da realização de concurso público - objeto desse estudo - o tema seleção de pessoas ganha uma grande importância, não apenas pela questão da eficiência da gestão organizacional, mas também porque esses novos funcionários exercerão funções de interesse público, transformando-se, portanto, em uma questão social.

É nesse contexto de seleção de pessoas para o serviço público, baseado em um processo de concurso público, que este trabalho objetiva analisar a percepção que os docentes, do curso de Administração de uma universidade federal do nordeste têm sobre o processo de seleção no qual participaram na condição de candidatos.

Dessa forma, os resultados deste estudo podem contribuir tanto para o tema de seleção de pessoas, mais especificamente no setor público, como para o aperfeiçoamento nos processos seletivos para docentes em universidade públicas.

\section{REFERENCIAL TEÓRICO}

\subsection{Competência}

A expressão "competência" tem sido ao mesmo tempo, um dos conceitos mais empregados e também mais controvertidos no jargão da administração contemporânea. Muitos confundem o significado de competência, com os de qualificação, atribuições, performance, sem contar os outros diferentes atributos que são tratados como competências (RUAS, 2001). No contexto da valorização de competências, o processo de seleção assume contornos diferenciados. De acordo com Abreu e Carvalho-Freitas (2009), essa abordagem é decorrência das mudanças ocorridas nas organizações que se tornaram mais flexíveis e polivalentes. Esse método mapeia as competências indispensáveis para as exigências organizacionais e a partir delas constrói-se o processo de seleção (entrevistas, jogos dinâmicos, provas situacionais).

Para Fleury e Fleury (2001) competência é uma palavra do senso comum que pode ser utilizada para designar uma pessoa com qualificação para realizar alguma coisa. Aliado ao conceito de competência está o de qualificação e de formação.

Fleury e Fleury (2001) salientam que no modelo taylorista e fordista de organização do trabalho, a qualificação, com frequência, é associada à posição que a pessoa ocupa, ou ao cargo, ou pelos conhecimentos, que podem ser classificados e certificados pelo sistema educacional. Contudo, houve uma transformação neste conceito a partir do modo de produção flexível (pós-fordismo/toyotismo), passando a ser compreendida como um tipo de conhecimento não restrito apenas ao técnico-operacional. "Na ótica deste modelo, a qualificação é concebida como sendo "adstrita" ao posto de trabaIho e não como um conjunto de atributos inerentes ao trabalhador" (MANFREDI, 1998, p. 3).

A qualificação passou, assim, "a depender menos de um saber-fazer técnico e mais da atitude, da comunicação e de traços de personalidade do trabalhador" (HELAL, 2006, p. 4). Para Hirata (1994) qualificação é uma relação social, resultado de uma correlação das forças capital e trabalho. Formação, por outro lado, consiste no ensino e aprendizagem visando a uma boa performance em uma tarefa específica ou em um conjunto de tarefas que constituam um trabalho ou atividade. No caso dos professores, vários autores como Morin (1991), Serres (1993) e Demo (2003), entre outros, defendem, há quase meio século, que a formação do professor do Ensino Fundamental até a Pós-Graduação passa pela identificação com a pesquisa como método de ensino.

$\mathrm{Na}$ universidade, ensino, pesquisa e extensão compõem o tripé que sustenta o fazer acadêmico. Esta tríade implicou, até o momento, uma intencionalidade e não a articulação que coloque em crise a fragmentação destes termos, estabelecendo um processo de hibridização no qual a interface entre cada um seja mais relevante do que a autonomia e o isolamento de suas 
partes. Em outros termos, para a educação, o ensino sem a pesquisa rapidamente torna-se obsoleto e a extensão sem pesquisa configura-se em voluntarismo, assim como não existe pesquisa que em sua aplicação não responda às demandas do ensino e da extensão (DEMO, 2003).

Nesse contexto, a competência do docente deve estar associada a essa complexidade de concepção do que seja o fazer universitário, ou seja, que não há distanciamento entre as dimensões ensino, pesquisa e extensão, mas há entre elas um diálogo dinâmico no qual os discentes estão envolvidos (DEMO, 2003).

\subsection{A Seleção docente como uma avaliação por pares}

A seleção desse profissional envolve a percepção de sua capacidade de articular a indissociabilidade prevista inclusive nos instrumentos legais da educação. No que se refere à forma de avaliação, feita através de bancas examinadoras, esta se assemelha a algumas das características e dificuldades da avaliação por pares, discutidas por Binotto, Hoff e Siqueira (2008) entre elas evidencia-se: o bloqueio de novas idéias, desmotivação de visões inovadoras ou não convencionais, geração de um ciclo vicioso em que um docente mal avaliado passa a adotar os mesmos critérios quando se torna banca de concurso.

Bence e Oppenheim (2004) usam o termo peer review para designar o método de controle de qualidade que usa experts independentes para fazer a análise de artigos submetidos a eventos, periódicos e propostas de pesquisa. Para estes autores essa abordagem deveria usar experts qualificados para avaliar o trabalho de experts não tão qualificados. Grivell (2006) é enfático ao afirmar que o avaliador é aquele que separa o "joio do trigo", para que seja assegurada a qualidade da produção. No caso dos concursos públicos para docentes seria possível estabelecer uma analogia, ou seja, são experts que vão selecionar profissionais para desempenhar atividades acadêmicas.

A consulta prévia aos pares coloca-se em um contexto de construção de consensos e verdades. Tal processo data do século XVII e teve como função central preservar a credibilidade da produção científica (DAVYT; VELHO, 2000). No que diz respeito aos concursos públicos seria a preservação da credibilidade do corpo docente/pesquisador que deve alimentar a produção da ciência no contexto das universidades.

Percebe-se que a avaliação por pares, seja em trabalho científico ou processo seletivo, longe de se aproximar do ideal, dentro da qual foi concebida, tende a estar configurada como um limite ao crescimento da ciência. Isso se deve ao fato de constituir-se, muitas vezes, de uma ferramenta para a ratificação do pensamento estabelecido (Binotto; Hoff; Siqueira, 2008).

No que se refere ao setor público, essa questão torna-se ainda mais complexa. Como apontam Silva, Mello e Torres (2013) a gestão de pessoas no setor público apresenta uma realidade diversa daquela encontrada no setor privado, por isso os gestores de pessoas naquelas instituições ainda têm um longo caminho a percorrer, principalmente no que se refere à gestão por competências.

Ao mesmo tempo em que o perfil do mercado de trabalho exige processos mais amplos de seleção, a rigidez dos processos públicos, determinados em leis e decretos, em alguns casos, podem provocar engessamento nos processos de contratação operacionalizados principalmente pelo concurso público (CAMÕES; PANTOJA; BERGUE, 2010). Rusaw e Rusaw (2008) evidenciam que a função do RH no setor público é crítica e visa à integração com os demais sistemas.

Considerando que o setor público, no Brasil, é um dos maiores agentes de contratação de pessoas e que, por sua vez, esses novos funcionários exercerão funções de interesse público, a 
forma de recrutamento e seleção pública constitui-se em uma questão, não apenas de eficiência da gestão organizacional, mas também, social. Essa questão é ainda mais interessante no contexto do ensino superior no país, que tem passado por profundas mudanças e uma considerável expansão (CRUBELLATE; MENDES; LEONEL JUNIOR, 2009).

Acredita-se que, sendo a universidade um espaço de inovação e geração de conhecimento, por essência deveria estar à frente em relação às mudanças de paradigma, inclusive em relação às características desejadas para seus profissionais. Além disso, como afirmam Galvão, Corrêa e Alves (2011), as instituições de ensino superior, como as demais instituições, sejam elas públicas ou privadas, precisam cumprir metas com o intuito de alcançar os seus objetivos estratégicos, o que requer um processo de seleção de pessoas eficiente.

\subsection{Seleção de pessoas}

A seleção de pessoal se configura como um processo de fundamental importância para qualquer organização. Limongi-França e Arellano (2002) defendem que estamos passando por um momento em que a competição é um fator presente nas organizações e isso reflete, também, na concorrência por profissionais qualificados. Vergilio (2006) acrescenta que um constante problema que os gestores de RH enfrentam está em encontrar o melhor talento.

Segundo Pontes (2008) para a maioria dos autores, seleção é o processo de escolha de candidatos entre aqueles recrutados. $\mathrm{O}$ autor concorda com esse conceito, mas diz que ainda falta uma coisa: a motivação do candidato. Para ele a seleção de pessoas não é unilateral e não deve levar em consideração apenas a qualificação e o potencial. Assim define seu conceito de acordo com Lobos (1979, p. 157).

O processo de Administração de Recursos Humanos, por meio do qual a empresa procura satisfazer suas necessidades de recursos humanos, escolhendo aqueles que melhor ocupariam determinado cargo na organização, com base em uma avaliação de suas características pessoais (conhecimentos, habilidades etc.) e de suas motivações.

Santos (1973) corrobora com Lobos (1979) e define seleção como um processo que visa escolher pessoas adaptadas para determinada ocupação ou ao perfil operacional. Segundo o autor, nem sempre, nesse processo, escolhem-se os candidatos que revelam aptidões ou capacidades em índices elevados. Ele afirma que, em princípio, são escolhidos aqueles candidatos que apresentam maior afinidade de expectativas e potencialidades com as expectativas e necessidades previstas para o cargo, ou seja, geralmente não são escolhidos os mais talentosos e sim os mais adequados a uma função em uma situação predeterminada.

Um enfoque diferente é apresentado por Limongi-França e Arellano (2002, p. 66) ao apresentarem um conceito onde a escolha do candidato é feita não pelo cargo oferecido, mas sim aquele que é mais adequado para a organização. "Seleção é a escolha do candidato mais adequado para a organização, dentre todos os recrutados, por meio de vários instrumentos de análise, avaliação e comparação de dados". Para estas autoras, contratar um funcionário cujo potencial é maior que a capacidade da empresa e não dar oportunidade das pessoas se desenvolverem e crescerem, provavelmente levará à desmotivação. Assim as organizações devem gerenciar as expectativas para evitarem sentimentos de desvalorização profissional do empregado. Da mesma forma, admitir um funcionário sem a qualificação necessária gerará tensão e ansiedade, estresse e até irritabilidade se a contratação não for gerenciada adequadamente, assim a organização deve investir em treinamento e capacitação de seus funcionários (LIMONGI-FRANÇA: ARELLANO, 2002). 
Um programa de seleção de pessoas, de acordo com Cascio (1998) e Gatewood e Field (1998), citados por Santos, Franco e Miguel (2003) envolve alguns passos, como: análise do cargo, identificação das dimensões de desempenho do cargo, identificação do conhecimento e habilidades necessárias para o cargos, desenvolvimento/seleção/validação de instrumentos medidas para acessar o conhecimento e habilidades do candidato, uso de tais instrumentos e medida no processo de seleção de candidatos. Tais instrumentos buscam verificar se o candidato se enquadra no perfil demandado.

A crítica de Santos, Franco e Miguel (2003) apoia-se no fato de que tais práticas valorizam as causas internas do comportamento como determinantes, e colocam em um segundo plano as condições ambientais. Nesse sentido, consideram que a proposta behaviorista radical é mais precisa ao analisar o comportamento do sujeito, pois avaliam que o ambiente é uma variável importante no resultado da interação do indivíduo com o seu meio.

Santos, Franco e Miguel (2003) argumentam que o behaviorismo radical não utiliza questionários e entrevistas como os instrumentos principais de seu processo de análise, mas principalmente, detém-se sobre as relações entre o comportamento e o ambiente. Não se apóia em traços de personalidade, mas estuda o comportamento único do sujeito, seu repertório, desta forma privilegiando sua singularidade. $O$ behaviorismo radical estabelece nexos entre os comportamentos relevantes dos indivíduos para o desempenho de uma dada atividade, ou seja, as variáveis contingenciais são consideradas em tal processo. A posição do behaviorismo radical aposta na dimensão do ambiente como variável fundamental (SANTOS; FRANCO; MIGUEL, 2003).

Nesse sentido, os autores sugerem que:

A análise de currículos, entrevistas e verificações de conhecimento podem oferecer contribuições importantes para um processo de seleção de pessoal. Mas a utilização de técnicas que possibilitem a observação direta de desempenhos parece ser muito mais efetiva na identificação das variáveis responsáveis pela manutenção do comportamento (SANTOS; FRANCO; MIGUEL, 2003, p. 240-241)

Tal perspectiva demandaria do processo de seleção ampliar a criação de ambientes que reproduzissem o contexto de trabalho e ainda incluir no processo de seleção parte do treinamento on-the-job.

Verifica-se a partir dos conceitos apresentados que existe uma diferença de concepção referente ao processo de seleção. Enquanto Lobos (1979) e Santos (1973) falam em seleção de pessoal adaptada ao cargo ou a ocupação, onde se escolhe não necessariamente os mais talentosos, mas sim os que mais se adéquam ao cargo oferecido, Limongi-França e Arellano (2002) apresenta a concepção de que a escolha do candidato não se faz apenas pelo cargo oferecido, mas sim para aquele que é mais adequado para a organização como um todo. Limongi-França e Arellano (2002) afirmam que a seleção não deve ser feita apenas pela avaliação da experiência e do conhecimento do trabalho a ser realizado. Para as autoras, é interessante conhecer aspectos relacionados à personalidade do candidato para verificar se a contratação é interessante para ambas as partes. Apresentam algumas técnicas utilizadas na seleção de pessoal, que para elas servem para diminuir a possibilidade de erro na escolha do candidato certo.

As autoras concordam com algumas das etapas apontadas por Pontes (2008), como as entrevistas, provas ou testes de conhecimento e avaliação de saúde. Segundo Limongi-França e Arellano $(2002$, p. 67), a entrevista é o instrumento mais importante do processo de seleção. Por isso, devem ser conduzidas por profissionais experientes e capazes de identificar que fatores de ordem pessoal possam interferir no processo (antipatia, atração, rejeição etc.). "O entrevistador deve ter sempre em mente as expectativas da área".

Outra técnica utilizada no processo de seleção é a aplicação de provas de conhecimento. Elas podem ser gerais, quando visam avaliar o grau de cultura geral do candidato, ou espe- 
cíficas, quando avaliam os conhecimentos profissionais que o candidato possui, imprescindíveis para o bom desempenho da função. "É importante que esses instrumentos sejam desenvolvidos e validados internamente na empresa para não eliminar bons candidatos" (LIMONGI-FRANÇA; ARELLANO, 2002, p. 69).

Para as autoras, os testes psicológicos são instrumentos padronizados que servem de estímulo a determinado comportamento do examinado, "visam predizer o comportamento humano com base no que foi revelado na situação de teste" (LIMONGI-FRANÇA; ARELLANO, 2002, p. 69).

\subsection{Seleção no setor público}

O principal instrumento de seleção na gestão pública é o concurso público, que de acordo com Marconi (2005) é uma tentativa de reduzir tendências ao favorecimento de alguns em detrimento de outros. As pessoas são contratadas a partir desse processo pelo regime estatutário, que atribui estabilidade no emprego como forma de coibir a perseguição política. Tais mecanismos de proteção imprimiram ao setor público certa rigidez que dificulta o acompanhamento das novas tendências do mercado de trabalho.

Essa estrutura de funcionamento fez com o que a área de recursos humanos assumisse mais o papel de departamento de pessoal do que um setor preocupado com a gestão das pessoas, em um contexto mais estratégico. Marconi (2005) enfatiza as principais funções de recursos humanos no governo, restrita ao processamento de tarefas administrativas e proposição de regulamentos, limitando muito a perspectiva de uma atuação mais estratégica.

Essa lógica de estruturação dos recursos humanos imprimiu uma perspectiva de carreira com cargos estreitos, mais vinculados a formação profissional do que necessariamente as competências demandadas pelo setor em que o funcionário atua. Além disso, os sistemas de progressão e gratificação estão apoiados no tempo de serviço, produzindo poucos incentivos para um desempenho diferenciado, favorecendo a acomodação e a ausência de motivação para inovação (MARCONI, 2005).

Esse dilema tem sido debatido pela Nova Gestão Pública que, segundo Guimarães (2000), é a tentativa de a gestão pública superar a ênfase na burocratização e instituir formas de gestão mais flexíveis que respondam as necessidades contemporâneas da sociedade.

Apoiado nos estudos de Ferlie et al. (1996), Guimarães (2000) apresenta quatro modelos que orientam a nova gestão pública: impulso para a eficiência, downsizing e descentralização, impulso para eficiência e orientação para o serviço público. A Figura 1 demonstra a articulação entre essas perspectivas.

Figura 1 - Modelos de administração pública

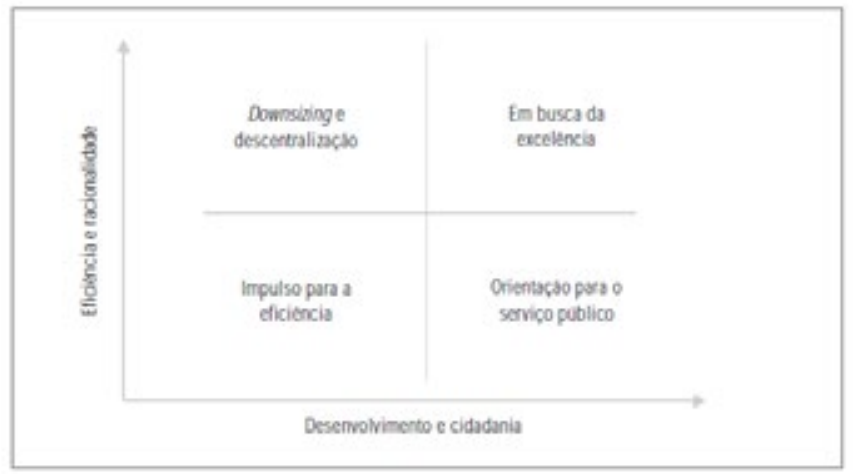

Fonte: Guimarães (2000, p. 130) 
Para o autor os modelos não são excludentes, fazem parte de um continuum que é utilizado em diferentes ênfases do setor público, considerando o foco de sua atuação. Os dois pressupostos os orientam:

O primeiro é que a prestação de serviços públicos deveria ser realizada tendo elementos norteadores a qualidade, eficiência e efetividade. O segundo é que as organizações públicas devem passar por um processo de racionalização organizacional, que implica a adoção de novos processos de gestão e de organização e divisão do trabalho, baseados em alianças e parcerias interorganizacionais, na organização matricial, em rede, por projeto, por processo (GUIMARÃES, 2000, p. 129)

É nessa perspectiva de um modelo híbrido que atenda a necessidades diferenciadas dos diversos setores da gestão pública, que Marconi (2005) defende a gestão estratégica de recursos humanos, como uma possibilidade de manter a flexibilidade necessária. $\mathrm{O}$ autor considera que a área de recursos humanos é facilitadora e deve proporcionar o perfil e o desenvolvimento dos servidores públicos, visando uma atuação mais eficiente.

Dessa forma, Marconi (2005) considera que é necessária uma estrutura híbrida no quadro funcional com diferentes modelos contratuais e regime de trabalho, organizados em 4 grupos de profissionais.

O primeiro seria de carreira de Estado, para aqueles profissionais que precisam de uma carreira longa e protegida, nesta se agrupam os gestores de políticas públicas, atividades jurídicas e regulatórias, defesa de interesses nacionais. Nesse caso, a via de acesso é o concurso e o modelo jurídico é o estatutário.

O segundo é composto por especialistas que dominam um setor específico ou determinada tecnologia, este poderiam ser contratos em uma combinação entre o regime estatutário e celetista, visto que nem sempre suas atividades são permanentes.

O terceiro grupo é composto de pessoas de escolaridade média ou fundamental, com contratos similares aos do setor privado, que seriam contratados de acordos com as demandas estratégicas, e, portanto, com maior flexibilidade para contratação e demissão de acordo com os interesses da gestão pública.

Finalmente Marconi (2005) descreve o grupo com características mais temporárias, de pessoas que tem um nível detalhado de conhecimento técnico para resolução de problemas pontuais, não sendo necessária sua permanência na carreira. Esses seriam contratados através de processos de terceirização.

Obviamente, tal proposta encontraria sérias dificuldades de implantação, visto que vivemos uma cultura do servido público estável, a flexibilização nas formas de contrato e carreiras certamente seria vista como um risco pelas entidades representativas dos trabalhadores, que interpretariam tal proposta como precarização das condições de trabalho, mas por outro lado, permitiria ao gestor publico um perfil flexível de contratação para o atendimento das demandas estratégicas da gestão.

Guimarães (2000) defende o uso do modelo de competências que romperia com as carreiras estreitas, preconizadas por Marconi (2005) para um modelo de recursos humanos baseado no planejamento, seleção, desenvolvimento e remuneração vinculados as competências essenciais definidas no planejamento estratégico da organização.

Siqueira e Mendes (2009) tecem uma critica a essa aproximação dos modelos da gestão publica e privada. Ainda que considerem que a gestão privada de recursos humanos pode contribuir para a construção de uma abordagem mais adequada ao setor público, indicam alguns riscos presentes nesse processo. Os autores consideram que ainda que se reconheça a necessidade de uma gestão mais voltada para os resultados, os mecanismos para viabilização desse processo, 
inspirados na gestão privada, podem incidir na deterioração das condições de trabalho.

Os autores avaliam que o modelo de competência, quando importado diretamente do setor privado, pode trazer como norte principal a dimensão da produtividade, recompensando e punindo os trabalhadores e não necessariamente permitindo processos de qualificação profissionais e enriquecimento de funções, pois pode se restringir a modelos de controle e vigilância de padrões desejados.

Portanto, não se trata da importação de um modelo pré-existente, mas do desenvolvimento de uma nova forma de gestão de recursos humanos que tenha como pressuposto o reconhecimento e respeito às diferenças, que permita o engajamento das pessoas em suas ações e o direito à expressão. Portanto, é um modelo que deve ser construído com a participação dos servidores públicos e da sociedade, visando a saúde do trabalhador (SIQUEIRA; MENDES, 2009).

\section{METODOLOGIA}

Foi realizada uma pesquisa exploratória com dados qualitativos complementados por dados quantitativos. Uma universidade federal do Nordeste que participa do REUNI foi escolhida como objeto de análise em função do processo de expansão que vem passando nos últimos três anos.

Fizeram parte como sujeitos da pesquisa 23 professores do curso de Administração da universidade, o que equivale a $88 \%$ dos docentes deste curso. Todos os sujeitos pesquisados participaram de processos seletivos como candidatos, sendo que 19 (82\%) dos respondentes foram entrevistados pessoalmente, e os que não foram encontrados receberam e responderam o questionário por e-mail. A amostra foi escolhida por conveniência, uma vez que se decidiu entrevistar apenas professores do curso de administração, sendo que todos os que foram abordados tiveram o interesse de participar da pesquisa.

Deve-se destacar que de todos os sujeitos pesquisados, dois eram professores substitutos na instituição, e, portanto, participaram de processos seletivos diferentes dos demais pesquisados, já que na universidade alvo da pesquisa os professores substitutos participam apenas de duas fases do processo seletivo (prova didática e análise de currículo), isto é, não participam da primeira fase que é a prova escrita. No entanto, para a presente pesquisa não será feita distinção entre professores efetivos e substitutos, já que o que se pretende investigar é a percepção dos candidatos acerca dos processos seletivos para docentes, independentemente se para um cargo efetivo ou temporário.

Os instrumentos de coleta de dados foram questionários com questões abertas e fechadas. O questionário 4 continha cerca de 35 questões, divididas em seis blocos: o primeiro bloco objetivava fazer uma caracterização dos respondentes, com questões como idade, sexo, titulação, tempo de docência; o segundo bloco buscou identificar a quantidade de participação em concursos públicos, quantidade de aprovações e reprovações, e se eles conheciam os perfis de candidato desejados nesses concursos; o terceiro bloco tratou sobre a percepção deles quanto às etapas do concurso (provas escritas, didáticas e análise dos currículos). O quarto bloco questionou sobre as bancas avaliadoras. Os últimos dois blocos tratavam sobre as questões de transparência e recurso, e sobre a percepção geral dos respondentes sobre o processo seletivo.

A aplicação dos questionários ocorreu na universidade, nas próprias salas dos professores entrevistados. O questionário foi entregue por um dos pesquisadores, e os próprios sujeitos da pesquisa responderam as questões, sempre com o auxílio do pesquisador em caso de dúvida sobre as questões. 4 Link para o questionário: https://docs.google.com/forms/d/1nH8r-hzBoPvEzOrfmLIBMA-zkIGNViiRTtVMx3fKoKM/
viewform?usp=send_form 
As categorias de análise para essa etapa serão:

a. percepção a respeito dos instrumentos que são utilizados no processo de avaliação dos candidatos; com base no terceiro bloco de questões, que vai da questão 5 até a 15 do questionário anexo.

b. percepção a respeito dos critérios de escolha adotados para composição dos membros da banca; com base no quarto bloco de questões, que vai da questão 16 até a 22 do questionário.

c. percepção sobre os processos de transparência e recurso no processo seletivo, com base no grupo de questões que vai da questão 23 a 31 .

d. percepção geral a cerca do processo seletivo; com base nas quatro últimas questões que eram perguntas abertas.

e. Para a análise das questões fechadas, foi utilizada a estatística descritiva por meio da distribuição de frequência e, para as questões abertas a análise interpretativa dos dados, de acordo com as categorias estabelecidas.

\section{RESULTADOS}

\subsection{Caracterizações dos respondentes}

Os dados coletados mostram que dos professores pesquisados $52 \%$ são homens e $48 \%$ são mulheres, $61 \%$ tem até 35 anos e os outros $39 \%$ tem entre 36 e 50 anos, portanto, relativamente bem distribuídos do ponto de vista do gênero, mas com alguma concentração em profissionais mais jovens.

Ainda que se considere a juventude do corpo docente, o tempo de docência em universidades indica que uma parcela significativa já trazia experiência universitária, pois, 39\% dos professores têm mais de sete anos de atividade, $17 \%$ tem entre quatro e seis anos, $22 \%$ tem três anos, $9 \%$ têm dois anos, e $13 \%$ tem um ano ou menos de docência. Já no que tange ao tempo de docência em universidades federais esse quadro se inverte, pois, $34 \%$ dos professores têm um ano ou menos de atividade, $35 \%$ tem dois anos, $9 \%$ três anos, $22 \%$ entre quatro e seis anos, e nenhum professor pesquisado têm mais de sete anos de atividade docente como professor de universidade federal (Figura 2). Esses dados mostram que os docentes do curso de Administração podem ser considerados de pouca idade, mas já com certa experiência em docência, visto que quase $40 \%$ deles têm mais de sete anos de docência em universidades. Entretanto, no que se refere à experiência em universidade federal, os dados indicam um processo de migração de universidades particulares para públicas. 
Figura 2 - Tempo de docência dos pesquisados

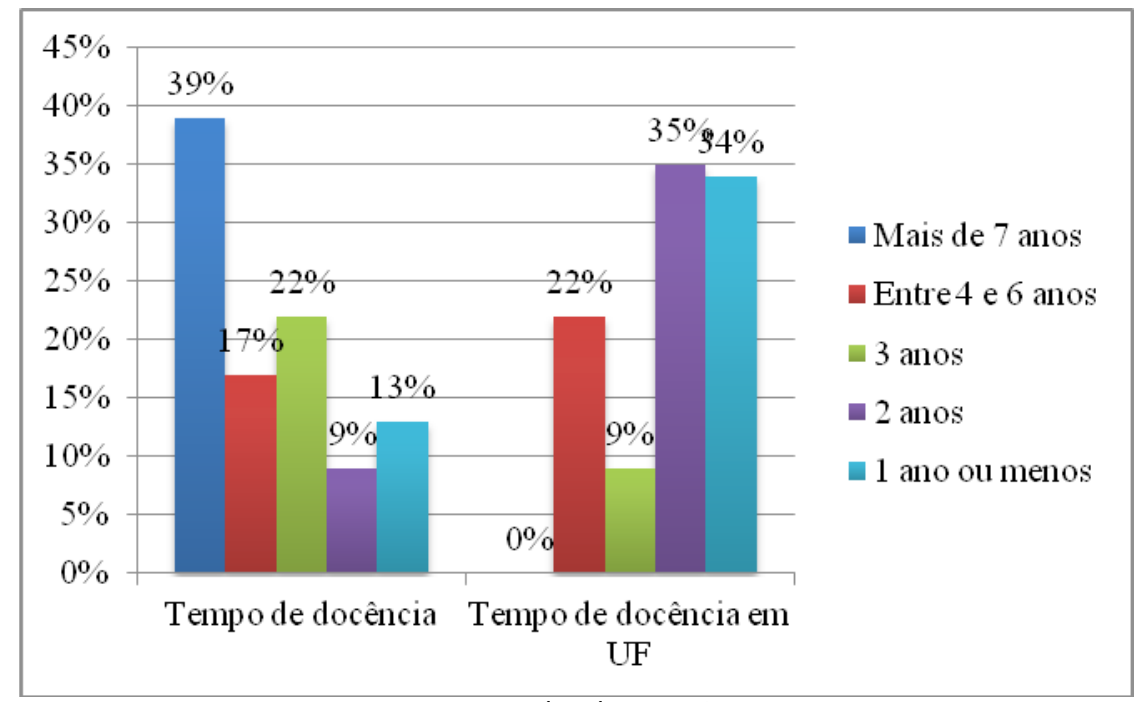

Fonte: Dados da pesquisa

Sobre a titulação de cada docente no que se refere à graduação, mestrado, doutorado e pós-doutorado, os dados mostram que $91 \%$ dos pesquisados responderam sobre a graduação, o que equivale a 21 professores. Constatou-se que destes, oito são formados em Administração, dois em Matemática, dois em Engenharia Agronômica, dois em Direito e um em cada uma das formações: Computação, Psicologia, Ciências Sociais, Economia, Ciências Humanas, Ciências Contábeis, Química e Tecnólogo em Cooperativismo. Percebe-se que a formação do quadro de professores do curso de Administração privilegia bastante a área de conhecimento, pois oito deles, $38 \%$ dos docentes, são graduados na área. As outras áreas indicadas refletem para o perfil do curso de administração que abriga em seu currículo uma diversidade de áreas.

Já em relação ao mestrado, 91\% já possuem, o que representa 21 professores, dois professores ou $9 \%$ dos pesquisados estão cursando no momento. Dos que já possuem, oito são em Administração, dois em Engenharia de Produção, dois em Direito, os demais um em cada formação: Engenharia Civil, Engenharia Mecânica, Ciências Humanas, Ciências Sociais, Fitotecnia, Meio -Ambiente e Desenvolvimento, área de Computação e Química. Dois professores (9\%) ainda não têm mestrado, mas já estão cursando, um em Ciências Contábeis e o outro em Administração. Deve-se destacar que estes professores estão na universidade como professores substitutos. Um respondente revelou apenas que tinha o nível de mestrado, mas não especificou em que área. Verificou-se que 30\% dos professores pesquisados, ou seja, sete professores, têm doutorado. Destes, dois em Administração, um em Engenharia de Transportes, um em Ciências Humanas, um em Ciências Sociais, um em Engenharia Mecânica, e um em Fitotecnia (Tabela 1). Nenhum professor tem pós-doutorado. 
Tabela 1 - Titulação dos sujeitos pesquisados

\begin{tabular}{c|c|c}
\hline \multirow{2}{*}{ Curso } & \multicolumn{2}{c}{ Titulação e Área de especialização } \\
\cline { 2 - 3 } & Mestrado & Doutorado \\
\hline Administração & 8 & - \\
\hline Engenharia de produção & 2 & 1 \\
\hline Engenharia de transportes & - & - \\
\hline Direito & 2 & - \\
\hline Eng. Civil & 1 & 1 \\
\hline Eng. Mecânica & 1 & 1 \\
\hline Ciências Humanas & 1 & 1 \\
\hline Ciências Sociais & 1 & - \\
\hline Fitotecnia & 1 & - \\
\hline Ciências da Computação & 1 & - \\
\hline Química & 1 & - \\
\hline Não especificou & 1 & 7 \\
\hline TOTAL & 1 & \\
\hline
\end{tabular}

Fonte: Dados da pesquisa

Apesar de estes dados mostrarem um percentual significativo de doutores na área do curso, preocupa-se o fato de que se forem levados em conta todos os professores do curso de Administração, apenas dois são doutores em Administração. Esse fato preocupa mais ainda pelo fato que são esses mesmo professores irão participar das bancas em outros concursos públicos para docentes da instituição, o que significa que, nem sempre os membros da banca têm competência na área do concurso que está avaliando, confrontando o que pregam Davyt e Velho (2000) quando dizem que apenas os cientistas com competência em determinada área podem avaliar o trabalho de seus colegas, já que somente eles podem emitir opinião formada e confiável.

Ao serem perguntados sobre a quantidade de concursos para docentes que eles tinham participado: $70 \%$ afirmaram ter participado de 1 a 3, 26\% de 4 a 6 , e apenas $4 \%$ de 7 a 10 . Esse dado mostra que os professores pesquisados foram aprovados já nos primeiros concursos prestados, o que de certa forma mostra um bom desempenho nestes processos seletivos.

Foi abordado sobre a quantidade de aprovações e reprovações nesses concursos. Dos respondentes $35 \%$ foram aprovados em apenas um concurso, $39 \%$ em dois concursos, $18 \%$ em três concursos, $4 \%$ em quatro concursos, e $4 \%$ em seis concursos. Com isso, a média de aprovação geral fica em torno de duas aprovações. Esses dados indicam que $65 \%$ dos docentes passaram em concurso para outras instituições. Isso significa que os professores pesquisados já foram servidores públicos de outras instituições ou preferiram ficar nesta universidade. Já em relação às reprovações, $48 \%$ têm apenas uma reprovação, $13 \%$ duas reprovações, $17 \%$ três reprovações, e $22 \%$ não tiveram nenhuma reprovação. A média de reprovação fica em torno de 1,25 reprovações. O quadro de reprovações, na perspectiva do behaviorismo radical, pode ser uma consequência da forma da seleção, que está mais próxima das qualidades individuais do que aquelas que relacionam o indivíduo ao ambiente que atuará (SANTOS; FRANCO; MIGUEL, 2003).

\subsection{Perfil do candidato desejado}

Outra pergunta feita tinha o objetivo de verificar se antes de iniciarem os concursos os professores conheciam o perfil de candidato desejado. Neste caso $87 \%$ dos respondentes afirmaram conhecer o perfil desejado e $30 \%$ disseram não conhecer. Esses dados mostram que, os 
processos seletivos através de concurso público estão alinhados com o que falam Limongi-França e Arellano (2002), na perspectiva da iniciativa privada, pois para elas as empresas devem buscar e atrair pessoas com o potencial adequado aos seus objetivos. Deve-se destacar que nesta questão, assim como nas demais que seguem no trabalho, as pessoas podiam marcar mais de uma opção de resposta, pois, por exemplo, uma pessoa pode conhecer o perfil de candidato em um concurso, e em outro não conhecer. Assim as somas das porcentagens podem ultrapassar $100 \%$.

Dos que afirmaram conhecer o perfil de candidato desejado, $90 \%$ disseram conseguir esta informação no edital do concurso, $10 \%$ conheceram de outros lugares como o currículo lattes e a internet, $5 \%$ procurou a universidade e se informou, e apenas $5 \%$ conheciam algum docente da universidade, o que mostra que a rede de relações entre os docentes não é significativa.

\subsection{Quanto às provas escritas, didáticas e análises dos currículos}

No que se refere às provas escritas dos processos seletivos, $65 \%$ afirmaram ser baseadas em pontos do edital, $48 \%$ ser questões abertas, e $13 \%$ ser questões fechadas, além disso, $4 \%$ afirmaram não ter feito prova escrita, que se referem aos professores substitutos. Como a maioria disse que as provas eram baseadas em pontos do edital, foi perguntado sobre tais pontos. Para 52\% os mesmos são direcionados a um candidato de área específica abordando conhecimentos bem delimitados, e também para $52 \%$ são abrangentes, envolvendo várias dimensões de conhecimento da área, dificilmente dominadas por um candidato, e ainda, 5\% afirmaram que os pontos não se relacionam com a vaga do concurso, e $5 \%$ disseram que varia de cada universidade (Figura 3). Percebe-se uma divisão das opiniões sobre aquilo que é solicitado em um processo de seleção, indicando que há uma dose de sorte e não meritocracia, visto que uma parcela significativa dos respondentes afirma não ser possível ter domínio sobre tudo que é solicitado.

Figura 3 - Indicação de bibliografia nos concursos

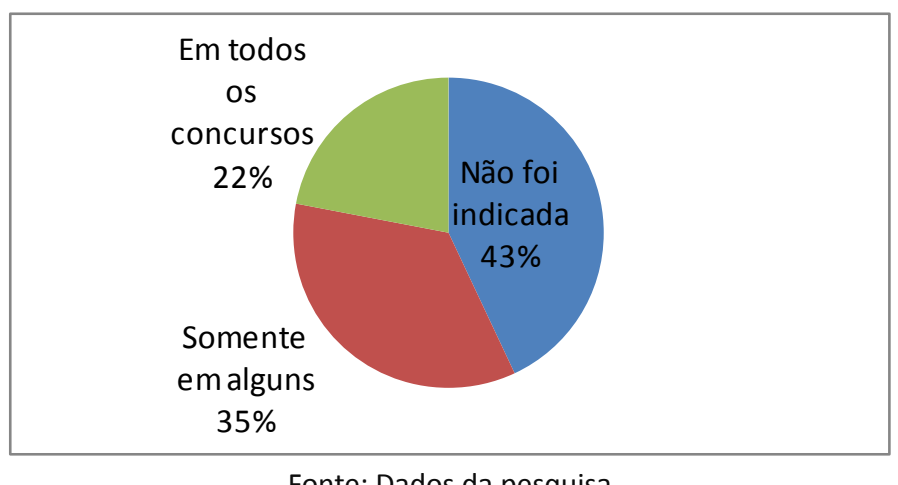

Fonte: Dados da pesquisa

Os dados sobre a indicação de bibliografia ajudam a explicar essa dose de sorte indicada anteriormente. Nos concursos prestados pelos respondentes, $43 \%$ afirmaram que não foi indicada bibliografia, $35 \%$ que somente em alguns concursos foi indicada e $22 \%$ disseram que em todos os concursos foi indicado bibliografia. A não indicação de uma bibliografia específica para o concurso pode significar que o candidato pode seguir uma linha de raciocínio ou uma perspectiva diferente da que os membros da banca podem ter, o que certamente irá prejudicar a avaliação do candidato. No caso em que não houve indicação de bibliografia, 100\% afirmaram definir a bibliografia de acordo com seus conhecimentos e, $12 \%$ citaram alternativas, como, amigos que estudam a mesma área, e também pesquisar sobre concursos já realizados na área. 
Já em relação à prova didática, foi perguntado se houve questionamento por parte das bancas avaliadoras durante essa etapa. Para $87 \%$ dos respondentes a banca fez questionamentos sobre o conteúdo apresentado, e para $13 \%$ a banca não fez questionamentos. No caso em que houve questionamentos, $84 \%$ dos respondentes afirmaram que a banca buscava o aprofundamento de uma questão específica, $32 \%$ que as questões expressavam uma tentativa de esclarecer algum ponto da aula, $5 \%$ que as questões expressavam a discordância do membro da banca com relação à abordagem dada na aula, e $5 \%$ disseram que a banca fez uma pergunta sobre a adequação à região em que o candidato iria atuar.

Sobre a avaliação do currículo, para 52\% nos concursos a experiência de ensino, pesquisa e extensão eram pontuadas de forma equilibrada, $43 \%$ afirmam que era prioritariamente 0 ensino, $17 \%$ que era a pesquisa (Figura 4 ).

Figura 4 - Importância dada na avaliação do currículo

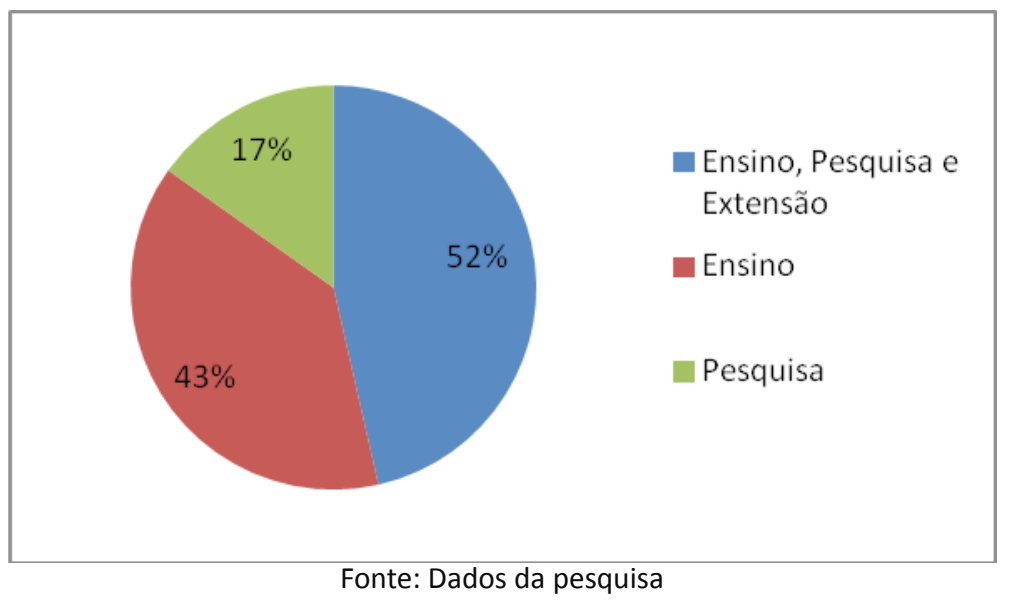

Nenhum respondente afirmou que a extensão era pontuada de forma significativa. Esses dados mostram que não existe uma boa sintonia no que é conhecido como o tripé do fazer acadêmico, na análise do currículo, pois a importância que é dada para as três dimensões de forma equilibrada é semelhante à importância dada somente ao ensino. Percebe-se ainda notório esquecimento para a atividade de extensão, já que nenhum respondente citou esta como prioritária na análise do currículo. Assim, ocorrendo a priorização de uma atividade em relação à outra se percebe uma falha no processo de seleção, já que dessa forma não se consegue atingir os objetivos estratégicos das instituições, que é muito importante para qualquer organização, conforme evidenciado por Jones e George (2008) e Dutra (2002).

\subsection{Quanto às bancas avaliadoras}

Constatou-se que $45 \%$ afirmaram que não foram divulgados os nomes da banca, $25 \%$ que foram divulgados durante a realização das provas, $18 \%$ no site da universidade, durante o período de inscrição, $14 \%$ no site da universidade, depois da homologação e antes do início do concurso, $14 \%$ no início do concurso antes de se iniciarem as provas, e apenas $5 \%$ afirmaram ter sido divulgado no edital do concurso. Esses dados evidenciam a fragilidade dessa dimensão do concurso, no que diz respeito à aproximação entre avaliador e avaliado, já que apenas em $5 \%$ dos processos o avaliado tem condições de conhecer o seu avaliador antes de iniciar o concurso. Para Demo (1996) esse desconhecimento pode atrapalhar o processo, já que para ele a avaliação é um processo de reconstrução que envolve a relação entre avaliador e avaliado em uma relação de diálogo. 
No que diz respeito à percepção que os entrevistados têm sobre os membros da banca, $45 \%$ afirmam que tais membros possuem produção na área do concurso, $41 \%$ que eles seguem a mesma linha teórica, $14 \%$ que os avaliadores possuem vínculo informal com a universidade, $14 \%$ ser indicação de conhecidos ou amigos. Já para $18 \%$ dos pesquisados, os componentes da banca apresentam pouca coerência entre currículo e avaliação realizada. Esses dados apontam que, menos da metade dos entrevistados afirma que os membros da banca conhecem a área do concurso; e que parte deles não considera os membros da banca com currículo adequado para avaliar os candidatos, o que certamente é um fator importante no momento da seleção, como defendem Davyt e Velho (2000).

Foram questionadas as percepções deles, enquanto candidatos, sobre os critérios de escolha das bancas. $38 \%$ afirmaram que um critério era ter formação acadêmica na área do concurso, $24 \%$ citaram ter lecionado a disciplina do concurso, três respostas foram citadas por $10 \%$ dos pesquisados: ter projeto de pesquisa e publicações na área do concurso; ser alguém que, além de conhecer a área, tenha contato com a universidade; referências obtidas junto a outros docentes. Com apenas $5 \%$ apareceu a opção experiência de docência superior aos candidatos do concurso, e $5 \%$ afirmaram que a banca é formada por um processo político (Gráfico 3). Nesta questão deve-se destacar que 33\% não sabem quais os critérios de escolha da banca avaliadora. Ter um processo seletivo no qual haja uma homogeneidade teórica entre avaliadores e avaliados pode comprometer a seleção uma vez que a diversidade de abordagem será um fator de exclusão (DAVYT; VELHO, 2000).

Figura 5 - Critério de formação das bancas

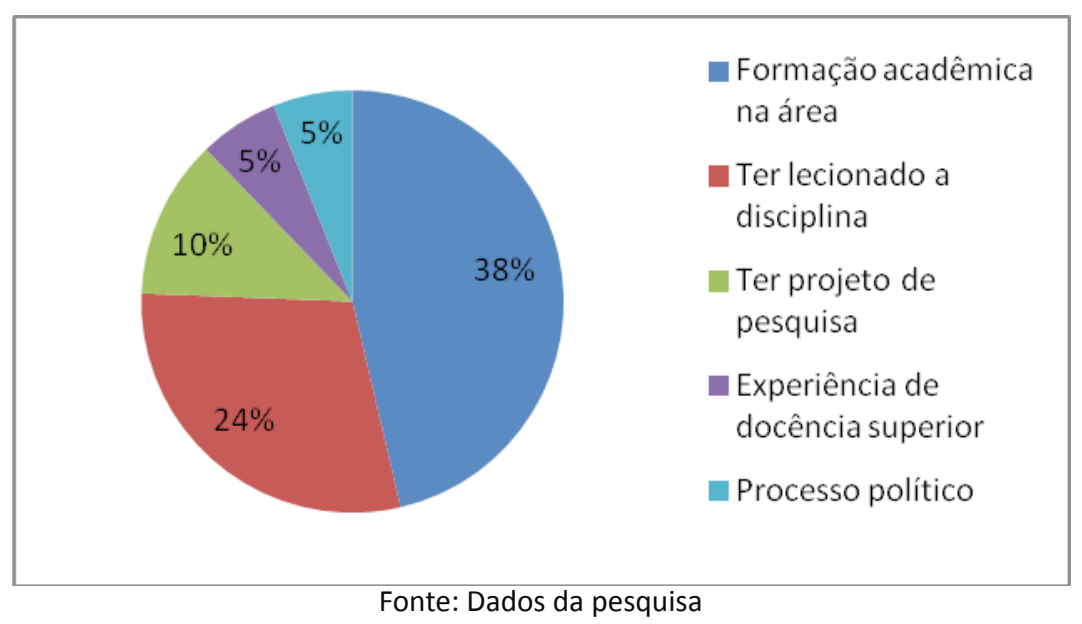

No que se refere à qualificação da banca, a percepção dos entrevistados é de que no que tange ao ensino, $65 \%$ afirmaram ser superior à dos candidatos, $17 \%$ disseram ser equivalente à dos candidatos, $26 \%$ dos respondentes afirmaram não ter feito essa avaliação, e nenhuma pessoa afirmou que a qualificação dos membros da banca era inferior à dos candidatos do concurso. Já no que se refere à pesquisa, $57 \%$ disseram que a qualificação da banca era superior à dos candidatos, $17 \%$ disseram ser equivalentes, $4 \%$ disseram ser inferior à dos candidatos, e $30 \%$ não fez essa avaliação. Quanto à extensão, apenas 30\% disseram ser superior, $9 \%$ equivalente, $13 \%$ inferior, e a maioria de $57 \%$ afirmaram não ter feito tal avaliação.

Foi questionado sobre o domínio da banca no que diz respeito aos pontos do concurso. Para $32 \%$ das pessoas, a análise do currículo dos membros da banca evidenciava sua competência para avaliar todos os pontos do concurso, $27 \%$ que a análise mostrava apenas parcialmente a competência, $5 \%$ que não evidenciava sua competência para avaliar todos os pontos do concur- 
so. Contudo, $45 \%$ dos respondentes afirmaram que os nomes dos componentes da banca não foram divulgados em tempo suficiente para que se pudesse proceder a essa análise. Dos pesquisados $9 \%$ disseram nunca ter feito essa análise.

Com esses dados percebe-se que muitos dos candidatos vão para as provas sem conhecerem os membros da banca, pois $45 \%$ afirmaram que não foram divulgados os nomes, e $25 \%$ não ter conhecimento sobre a banca antes de iniciarem as provas. Além disso, boa parte dos candidatos diz não conhecer os critérios de escolha da banca, o que mostra uma falha na transparência do processo.

Apesar de alguns não conhecerem os critérios de escolha das bancas, são poucos os que afirmam que tais membros apresentam pouca coerência entre currículo e avaliação realizada. Além disso, $65 \%$ dos pesquisados dizem que os membros da banca possuem qualificação superior no que diz respeito ao ensino, e $57 \%$ que é superior na pesquisa. Mais uma vez é dada pouca importância a atividade de extensão, pois $57 \%$ dos respondentes não fizeram avaliação sobre a atividade extensionista dos membros da banca, e apenas $30 \%$ que a banca é superior neste tipo de atividade.

Porém, surge uma incoerência no fato de que apesar de serem considerados superiores tanto no ensino quanto na pesquisa, apenas $32 \%$ dos pesquisados afirmam que a análise do currículo da banca evidencia a competência para avaliar todos os pontos do concurso. Isso preocupa, pois como é um processo que envolve o julgamento de pessoas, a confiabilidade passa a ser determinada pela confiabilidade dos avaliadores (IVANCEVICH, 2008).

\subsection{Quanto aos instrumentos, transparência e recursos}

Outra questão diz respeito à percepção sobre os instrumentos utilizados na avaliação de candidatos nas provas escritas, didáticas e também na análise do currículo. Na prova escrita, $86 \%$ consideram ser adequados e $14 \%$ limitados. Entre os motivos das limitações, foi citado que os sorteios dos pontos tornam o processo duvidoso e que os critérios de correção não são claros. Na prova didática, $78 \%$ percebem ser adequados, e $22 \%$ limitados. Foi citado como limitações o fato de não ter ocorrido discussão do assunto e a avaliação subjetiva dos critérios, onde aparecem notas destoando de outros membros da banca. Na etapa de análise do currículo, $70 \%$ disseram ser adequados e $30 \%$ limitados. Como limitação foi dito que a análise é restrita ao formulário da instituição, e que os pesos para cada dimensão analisada eram desproporcionais.

Figura 6 - Avaliação dos instrumentos utilizados

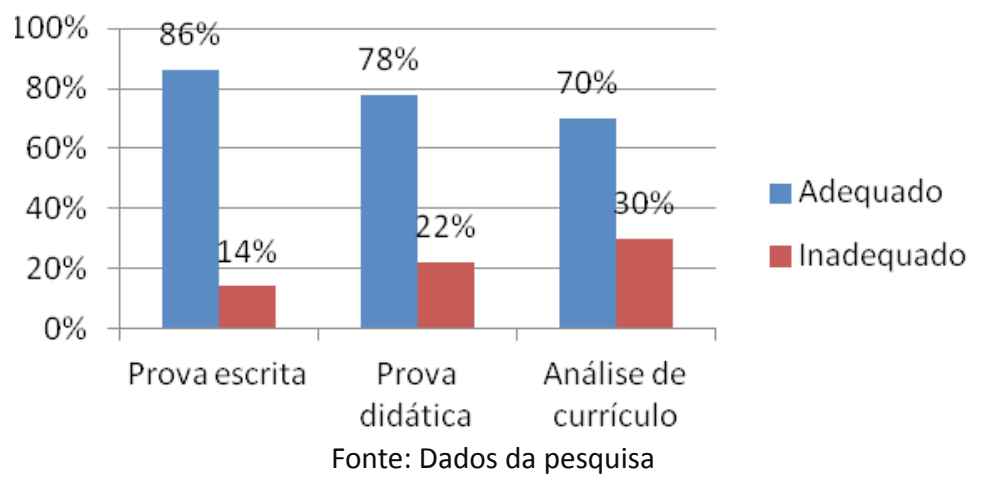

Com os dados apresentados é possível afirmar que os processos estão satisfazendo os candidatos, pois os índices de respondentes que afirmaram serem adequadas às provas escritas, didáticas e a análise do currículo são bem expressivos, porém essa satisfação não é clara em todas as questões que se seguem. 
Questionou-se sobre a transparência nas três etapas do concurso, prova escrita, didática e análise do currículo. No que diz respeito a oferecer informações corretas no tempo adequado, os índices foram $70 \%, 73 \%$ e $68 \%$, nas provas escritas, didática e análise do currículo, respectivamente. Ou seja, esses percentuais de respondentes afirmaram que na prova escrita, didática e análise de currículo foram oferecidas as informações corretas do tempo adequado. Em relação a oferecer ampla possibilidade de defesa do candidato com relação a possíveis divergências quanto ao processo de avaliação, os índices foram $25 \%, 23 \%$ e $32 \%$, respectivamente. No quesito possibilitar acesso a informações relativas à banca, foi $25 \%, 14 \%, 14 \%$ respectivamente. Em possibilitar o acesso a informações sobre os critérios de avaliação, foi de $20 \%, 18 \%, 18 \%$ nas três etapas. Já em relação a possibilitar a impetração de recursos quanto ao processo, foram de $30 \%$, $41 \%$, e $36 \%$, respectivamente às três etapas. Esses dados estão sintetizados na Tabela 2.

Tabela 2 - Percepção dos respondentes sobre a transparência nas três etapas do concurso

\begin{tabular}{|c|c|c|c|}
\hline \multirow{2}{*}{} & \multicolumn{3}{|c|}{ Etapa do Concurso } \\
\cline { 2 - 4 } & Prova Escrita & Prova Didática & Análise do Currículo \\
\hline Informações corretas no tempo adequado & $70 \%$ & $73 \%$ & $68 \%$ \\
\hline $\begin{array}{c}\text { Ampla possibilidade de defesa do candidato com } \\
\text { relação a possíveis divergências quanto ao pro- } \\
\text { cesso de avaliação }\end{array}$ & $25 \%$ & $23 \%$ & $32 \%$ \\
\hline Acesso a informações relativas à banca & $25 \%$ & $14 \%$ & $14 \%$ \\
\hline Acesso a informações sobre os critérios de avaliação & $20 \%$ & $18 \%$ & $18 \%$ \\
\hline Impetração de recursos quanto ao processo & $30 \%$ & $41 \%$ & $36 \%$ \\
\hline
\end{tabular}

Fonte: Dados da pesquisa

Nesta questão compreende-se que as informações corretas são oferecidas no tempo adequado nas três etapas do concurso, porém são oferecidas poucas possibilidades de defesa do candidato com relação a divergências no processo de avaliação, poucas informações relativas à banca, e poucas informações sobre os critérios de avaliação, assim como, possibilidade restrita de impetração de recursos quanto ao processo.

Assim, no que se refere ainda à transparência do concurso, ao serem questionados sobre quais itens precisam ser melhorados dentro do processo seletivo, o mais solicitado, com $61 \%$, foi possibilitar o acesso às informações relativas à banca, com $44 \%$ oferecer as informações corretas no tempo adequado aos candidatos, $39 \%$ oferecer ampla possibilidade de defesa do candidato com relação a possíveis divergências quanto ao processo de avaliação, 39\% possibilitar o acesso a informações sobre os critérios de avaliação, $17 \%$ possibilitar a impetração de recursos quanto ao processo.

Ainda surgiram alternativas de melhorias, como a divulgação da qualificação das bancas, e divulgação das bancas com antecedência. Parece ser evidente que a principal preocupação dos candidatos é em relação às informações sobre as bancas avaliadoras, estas precisam ser mais bem divulgadas, oferecer mais possibilidade de defesa e mais esclarecimentos aos candidatos sobre os processos de avaliação. Porém, percebe-se também certa incoerência no que diz respeito a oferecer as informações corretas no tempo adequado, pois no primeiro momento viu-se uma satisfação neste quesito, e no decorrer da discussão aparece como um ponto central a ser melhorado.

Quanto aos recursos contra os resultados, perguntou-se aos pesquisados se já tinham entrado com recurso questionando a avaliação, 91\% afirmou não ter entrado, e apenas $9 \%$ ter recorrido. Entre os motivos para entrar com recurso foram citadas a infra-estrutura inadequada da instituição e a transparência no processo seletivo e perfil da banca. $E$ todos que entraram com recurso afirmaram que este não foi acatado. Dos respondentes $94 \%$ disseram que em nenhuma oportunidade a banca alterou o resultado do concurso e apenas $6 \%$ disseram participar de concurso que teve seu resultado alterado. 
Em outro questionamento foi perguntado se eles já tinham sofrido algum constrangimento em concursos, $70 \%$ afirmaram nuncae $30 \%$ já ter sofrido. Entre alguns motivos estão casos em que a comissão e a banca interromperam o processo seletivo sem maiores explicações; outro em que o professor seria contratado apenas para ministrar aula e a banca questionou o candidato sobre a possibilidade dele em atuar na extensão e na pesquisa; e ainda que os avaliadores não prestavam atenção ao candidato; e também que houve a pressão excessiva dos candidatos concorrentes.

\subsection{Percepção dos respondentes sobre o processo}

Os respondentes foram indagados se eles consideravam que os candidatos de um concurso tinham plenas condições de demonstrar suas qualidades, durante o processo, para atuarem em uma universidade federal, $60 \%$ responderam que não. Entre os motivos são que: fatores externos poderiam atrapalhar como a ansiedade e o nervosismo, o tempo é limitado, os pontos sorteados poderiam não corresponder com a área de maior domínio do professor, uma prova não consegue avaliar as inúmeras situações passadas por um docente, e que normalmente só é avaliada a questão do ensino, assim o método de avaliação é limitado. Nesta fase surge outra incoerência, pois se antes os pesquisados apontaram como adequados os instrumentos utilizados na avaliação das três etapas, agora, em sua maioria, eles não consideram o processo como eficaz para o candidato mostrar todas suas qualidades. Assim, os métodos de avaliação e seleção de docentes através do concurso precisam ser revisados, pois como afirma Limongi-França e Arellano (2002) admitir um funcionário sem a qualificação necessária gerará tensão e ansiedade, estresse e até irritabilidade se a contratação não for gerenciada adequadamente.

Os outros $40 \%$ consideram que durante o concurso o candidato tem condições de mostrar suas qualidades para atuarem em uma universidade federal, pois no concurso exigem-se demonstrações de conhecimento na escrita, didática e no currículo.

Foi questionado se os docentes entendem o processo de avaliação na banca de concurso como uma avaliação por pares, ou seja, aquele em que um expert avalia o trabalho do outro, conforme apontam Bence e Oppenheim (2004). Dos responderam, 85\% afirmaram que sim. Estes citaram como principais vantagens desse tipo de avaliação, o domínio do assunto pelo membro da banca, que assim tem capacidade para selecionar o candidato melhor preparado e mais adequado ao perfil requerido pela instituição. Tal percepção está alinhada com a proposição de Davyt e Velho (2000). Outros $15 \%$ disseram não entenderem essa avaliação como uma avaliação por pares, pois o processo é unidirecional, no sentido do avaliador para o avaliado, e que é um processo com vício político.

Quanto ao processo de avaliação realizado na universidade, $40 \%$ consideram positivo, sendo citados adjetivos como: organizado, legítimo, justo, transparente e sério. Porém, $60 \%$ afirmaram que deixou a desejar, e, portanto precisa melhorar em alguns quesitos, como: divulgação de informações, número de vagas e perfil do candidato desejado. Porém, a maior preocupação dos respondentes foi em relação à formação, critérios de seleção e transparência da banca, assim como dos critérios de avaliação, e dos recursos, o que corrobora com o que defende Ivancevich (2008) e Davyt e Velho (2000) sobre a credibilidade do corpo docente/pesquisador. A partir desses dados referentes à universidade, pode-se afirmar que o processo seletivo nessa instituição apresenta preocupações semelhantes a dos demais concursos prestados pelos docentes participantes da pesquisa, onde as questões relativas às bancas avaliadoras surgem como principais problemas.

Ao final abriu-se espaço para sugestões de melhorias no processo de seleção de docentes. Surgiram sugestões como a divulgação da banca com antecedência; rever as resoluções que regem os concursos; criação de critérios de seleção balizados na área do conhecimento para a formação de ban- 
cas; melhor determinação do perfil do professor desejado, onde a contratação deveria ser feita com base na área de interesse da universidade, e não na disciplina a ser ministrada; maior transparência no processo; inclusão de análise de memorial e entrevista com o conselho do curso, para que possam avaliar o candidato; apresentação de projeto de ensino, pesquisa e extensão a ser desenvolvido após a aprovação; e melhoras na estrutura física da instituição para os candidatos durante o processo.

\section{CONSIDERAÇÕES FINAIS}

O objetivo dessa pesquisa foi analisar a percepção que os docentes, do curso de Administração de uma universidade federal do nordeste têm sobre o processo de seleção no qual participaram na condição de candidatos.

Este estudo é marcado por várias incoerências, uma delas surge no fato de que apesar dos regulamentos não deixarem claro o papel que devem exercer dentro da universidade, os docentes dizem conhecer o perfil de candidato desejado pela instituição, o que é muito importante para qualquer instituição, pois a partir daí pode-se cobrar deles uma atitude mais estratégica do que funcionalista (DAVEL; VERGARA, 2001).

Outra incoerência reside no fato de que, apesar de na universidade, ensino, pesquisa e extensão comporem o tripé que sustenta o fazer acadêmico, não foi isso que se pode perceber em relação ao processo seletivo na concepção dos docentes pesquisados. Para eles a atividade de ensino, sozinha, é pontuada quase que da mesma forma que é pontuada as três atividades em conjunto, além disso, percebe-se uma desvalorização da atividade de extensão.

Apesar de serem consideradas superiores aos candidatos no que diz respeito ao ensino e a pesquisa, os membros da banca não detêm ampla credibilidade por parte dos mesmos, pois apenas $32 \%$ afirmam que a análise do currículo da banca evidencia a competência para avaliar todos os pontos do concurso. Vale ressaltar ainda, que diferente do que ocorre em outras empresas, o processo de seleção não é conduzido por profissionais da área de seleção de pessoas, mas trata-se de uma seleção por pares. Isso é preocupante, pois como foi dito anteriormente, um erro na escolha pode trazer grandes prejuízos para a instituição, principalmente pelo fato da estabilidade presente na esfera pública, onde equívocos cometidos durante o processo de seleção encontram pouca possibilidade de correção ou provocam desgastes para a instituição.

Em um primeiro momento, quando questionados de forma individual, os instrumentos utilizados nas três etapas do processo seletivo são satisfatórios para os candidatos, porém ao se questionar sobre o processo no geral o índice de desaprovação é de $60 \%$. Assim, é interessante que o processo seletivo seja revisto em sua concepção geral.

Constatou-se que as bancas avaliadoras são os principais alvos de críticas dos candidatos. Necessita-se de mais transparência, desde a formação, critérios de seleção e divulgação das bancas, assim como dos critérios de avaliação, e dos recursos impetrados pelos candidatos. Uma solução para o problema da formação de bancas de concursos seria a composição de bancas avaliadoras que aliasse formação acadêmica na área do concurso, realização de pesquisas na área, e uma divulgação dos membros já no edital do concurso. Já no que se refere aos critérios de avaliação e de recursos, poderia ocorrer uma divulgação melhor dos critérios utilizados na avaliação dos candidatos, como por exemplo, na disponibilização dos espelhos de correção de provas, e das respostas aos recursos interpostos.

Alternativa seria a inclusão da perspectiva do Behaviorismo Radical (SANTOS; FRANCO; MIGUEL, 2003) que sugere a inclusão de situações ambientais próximas daquelas que serão vividas pelos candidatos, como forma de ampliar as possibilidades de compreensão do seu comportamento no ambiente de trabalho. 
De forma geral, na visão dos respondentes, o processo realizado pela universidade apresenta as mesmas características dos demais, isto é, poderia ser melhorado em alguns quesitos, como na divulgação de informações, especialmente no que diz respeito à formação, critérios de seleção, e transparência da banca, assim como dos critérios de avaliação, e dos recursos.

O mercado e a sociedade têm demandado das organizações qualidade nos serviços e produtos oferecidos. No caso das universidades esse é um fator importante a ser considerado, pois ela oferece a este mercado os profissionais que conduzirão as empresas públicas e privadas. Nesse sentido, a formação de profissionais competentes tem estreita vinculação com os docentes que são contratados.

Como limitações deste estudo pode-se considerar o fato de ter sido realizado em apenas uma universidade, que além de ser considerada nova, vem passando por um processo de expansão muito grande nos últimos três anos.

Recomenda-se que em estudos futuros sejam entrevistados não apenas professores, mas também membros de comissão de seleção, chefes de departamentos e coordenadores de cursos, para que se possa compreender o processo de seleção em diferentes visões e contextos.

\section{REFERÊNCIAS}

ABREU, C. V.; CARVALHO-FREITAS, M. N. de. Seleção por competências: A percepção dos profissionais de RH sobre o método de seleção por competências. Pesquisas e Práticas Psicossociais. n.3, v. 2, São João del-Rei, p. 225-234, Mar. 2009

BECK, U. Capitalismo sem trabalho. Ensaios FEE. Porto Alegre, v.18, n. 1, p. 41-55, 1997.

BENCE, V.; OPPENHEIM,C. The influence of peer review on the research assessment exercise. Journal of Information Science. v. 30. n.4, p. 347-368, 2004.

BINOTTO, Erlaine, HOFF, Débora Nayar; SIQUEIRA, Elisabete Stradiotto. Peer Review e a qualificação da produção científica: limites e avanços. XXXII Encontro da Anpad, Anais... Rio de Janeiro, RJ, setembro de 2008.

BITENCOURT, C. C. A gestão de competências gerenciais e a contribuição da aprendizagem organizacional. RAE, v. 44, n. 1, p. 58-69, Jan./ Mar., 2004.

CASCIO, Wayne F. The Future World of Work: Implications for Human Resource Costing and Accounting. Journal of Human Resource Costing \& Accounting, v. 3 n. 2, p.9-19, 1998.
CAMÕES, M.R.de S., PANTOJA, M.J. e BERGUE, S.T. Gestão de pessoas: bases teóricas e experiências no setor público/organizado. Brasília: ENAP, 2010.

CASTELLS, M.. A sociedade em rede. São Paulo: Paz e Terra, 1999.

Coordenação de Aperfeiçoamento de Pessoal de Nível Superior. Disponível http//: www. capes.gov.br. Acesso 25 jul. 2014.

CRUBELLATE, J. M.; MENDES, A. A.; LEONEL JUNIOR, R; da $S$. Respostas estratégicas e qualidade de ensino superior em organizações de ensino superior (IES) do estado do Paraná. Rev. Adm. UFSM, Santa Maria, v.2, n. 1, p. 116129, jan./abr. 2009.

DAVEL, E.; VERGARA, S. C. Gestão com Pessoas, Subjetividade e Objetividade nas Organizações. In: DAVEL, E.; VERGARA, S. C. Gestão com Pessoas e Subjetividade. São Paulo: Atlas, 2001. p. 31-56.

DAVYT, A; VELHO, L. A avaliação da ciência e a revisão por pares: passado e presente. Como será o futuro? História, Ciências e Saúde Manguinhos, v. 7 n.1. p. 93-116, Rio de Janeiro, 2000 mar/jun.

DEMO, P. Avaliação sob o olhar propedêutico. São Paulo: Papirus, 1996. 
DEMO, P. Educar pela pesquisa. Campinas: Autores Associados, 2003.

DUTRA, J. S. Gestão de Pessoas: modelo, processos, tendências e Perspectivas. São Paulo: Atlas, 2002. ed. São Paulo: LTR, 2008.

Ferlie E, Pettigrew A, Ashburner, Fitzgerald L. The New Public Management in Action. Oxford University Press, Oxford, UK, 1996.

FLEURY, M. T. L. FLEURY, A. Construindo o conceito de competências. RAC, Edição Especial p. 183-196, 2001.

GALVÃO, H. M.; CORRÊA, H. L.; ALVES, J. L. Modelo de avaliação de desempenho global para instituição de ensino superior. Rev. Adm. UFSM, Santa Maria, v. 4, n. 3, p. 425-441, set./ dez. 2011.

GATEWOOD, R. D.; FIELD, H. S. Human resource selection. NY: Harcourt Brace College, 1998.

GUIMARÃES, Thomas de Aquino. A nova administração pública e a abordagem da competência. Revista de Administração Pública, Rio de Janeiro, v. 34, n. 3, p. 125-140, maio/jun. 2000.

GRIVELL, L. Through a glass darkly. EMBO reports. v. 7, n. 6, p. $566-570,2006$.

HELAL, D. H. Exigências Profissionais em Organizações Pós-Fordistas: das Qualificações ao Modelo de Competência. XXVI ENEGEP. Anais... - Fortaleza, CE, Brasil, 2006.

HELOANI, J. R. Organização do Trabalho e Administração: Uma visão multidisciplinar. São Paulo. Cortez, 1994.

HIRATA, Helena. Da polarização das qualificações ao modelo de competência. In: Ferretti, Celso J. e outros. Novas tecnologias, trabalho e educação: um debate multidisciplinar. Petrópolis, Vozes, 1994, p. 124-138.

HORTON, S. Introduction - the competency movement: its origins and impact on the public sector. The International Journal of Public Sector Management, v. 13, n. 4.p. 306-318, 2000.

IVANCEVICH, J. M. Gestão de Recursos Humanos. São Paulo: Mc Graw-Hill, 2008.

JONES, G.; GEORGE, J. Administração Contemporânea. São Paulo: McGraw-Hill, 2008.

LIMONGI-FRANÇA, A. C.; ARELLANO, E. B. A função Recrutamento e Seleção. In:

FLEURY, M. T. L. (Org.) As Pessoas na Organização. 4. ed. São Paulo: Gente, 2002.

LOBOS, J. A. A administração de Recursos Humanos. São Paulo: Atlas, 1979.

MANFREDI, S. M. Trabalho, qualificação e competência profissional - das dimensões conceituais e políticas. Educação e Sociedade. v.19 n.64, p. 13-49, Campinas, Sept. 1998.

MARCONI, Nelson. Políticas Integradas de Recursos Humanos para o Setor Público. In: Evelyn Levy; Pedro Aníbal Drago. (Org.). Gestão Pública no Brasil Contemporâneo. 1ed.São Paulo: Edições Fundap, 2005

MARRAS, J. P. Administração de Recursos Humanos: do operacional ao estratégico. São Paulo: Futura, 2000.

MICHAELS, E.; HANDFIELD-JONES, H.; AXELROD, B. A guerra pelo talento: o talento como diferencial estratégico entre as empresa. Rio de Janeiro: Campus, 2002

MORIN, E. O método IV - as idéias: A sua natureza, vida, habitat e organização. Portugal: Europa-América, 1991.

PONTES, Benedito Rodrigues. Planejamento, Recrutamento e Seleção de Pessoal. 5. ed. São Paulo: LTr, 2008.

QUEIROZ, Ana Carolina; ALBUQUERQUE, Lindolfo Galvão de; MALIK, Ana Maria. Gestão 
estratégica de pessoas e inovação:estudos de caso no contexto hospitalar. R.Adm., São Paulo, v.48, n.4, p.658-670, out./nov./dez. 2013

RUAS, R. Mestrado executivo, formação gerencial e a noção de competências: provocações e desafios. In: ENANPAD, Anais... Campinas, 2001.

RUSAW, A. C.; RUSAW, M. F. The Role of HRD in Integrated Crisis Management: A Public Sector Approach. Developing Human Resources, v. 10, n.3, p. 380-396, June, 2008.

SANTOS, J.G.W, FRANCO, R.N.A., MIGUEL, C.F. Seleção de pessoal: considerações sobre a perspectiva Behaviorista Radical. Psicologia: Reflexão e Critica, v. 16, n.2, p. 235-243, 2003.

SANTOS, O. B. Psicologia aplicada à orientação e seleção de pessoal. São Paulo: Pioneira, 1973.

SENNETT, R. A corrosäo do caráter consequências pessoais do trabalho no novo. Rio de Janeiro: Record, 2000.

SERRES, M. Filosofia mestiça: Le tiers instruit. Rio de Janeiro: Nova Fronteira, 1993.

SIQUEIRA, Marcos Vinicius Soares, MENDES, Ana Magnólia. Gestão de Pessoas no setor público e a reprodução do discurso do setor privado. Revista do Serviço Público. Brasília, v. 60, n.3, p. 241-250, jul/setembro, 2009.

SILVA, F. M. da; MELLO, S. P. T. de; TORRES, I. A. C. O que se discute sobre gestão por competências no setor público: um estudo preliminar das construções. Rev. Adm. UFSM, Santa Maria, v. 6, n. 4, p. 685-693, Dez. 2013.

TOFFLER, A. A riqueza revolucionária. São Paulo, Futura, 2007.

ULRICH, D.(org.). Recursos humanos estratégicos: novas perspectivas para os profissionais de RH. 3.ed. São Paulo: Futura, 2000.

VERGILIO, M. E. Práticas de Seleção e
Alocação de Profissionais no Contexto Atual da Gestão Estratégica de Pessoas. 2006. 163f. Dissertação (Mestrado em Engenharia de Produção) - Programa de Pós-Graduação em Engenharia de Produção da Faculdade de Engenharia Mecânica e de Produção, Santa Bárbara D’Oeste, Universidade Metodista de Piracicaba, 2006.

Beneficiário de auxílio financeiro do CNPq.v 